\title{
A Simple Model for Pollution Dispersion in a Convective Boundary Layer
}

\author{
Roland Stull and Bruce Ainslie \\ The University of British Columbia, Vancouver, British Columbia, Canada
}

(Manuscript received 5 September 2005, in final form 14 April 2006)

\begin{abstract}
A simplified model for dispersion in a convective boundary layer is presented and is used to diagnose crosswind-integrated concentrations, ground-level concentrations, and vertical plume spread over flat terrain for various release heights. The model parameterizes the long-wavelength oscillation of the timeaveraged plume centerline versus downwind distance under unstable conditions, using a simple sine wave. This wave is phase shifted to account for the influence of source height and is damped toward the midmixed layer to account for the well-mixed end state of convective dispersion. This model represents an improvement over a previous model in two ways. First, vertical dispersion about the oscillating timeaveraged centerline is parameterized using a lognormal distribution instead of a Gaussian distribution so as to give better ground-level concentration. Second, to account for the addition of surface-layer sheargenerated turbulence to a convective boundary layer, the wavelength of the time-averaged oscillation is stretched as a function of the ratio of friction velocity to the Deardorff convective velocity scale. Results are tested against published laboratory, large-eddy simulation, and field data and are compared with the dispersion scheme used in the AERMOD regulatory dispersion model. In general, the simplified convective dispersion model provides close agreement with the observations and simulations. The utility of a buoyancy velocity to serve as a convection scale is also demonstrated.
\end{abstract}

\section{Introduction}

For continuous pollutant emissions from a point source such as a smokestack, the centerline of the plume loops up and down in a convective atmospheric boundary layer $(\mathrm{ABL})$ or mixed layer in response to vigorous thermal updrafts and downdrafts (Fig. 1a). Such behavior is typically observed with light mean wind over heated surfaces, such as fair-weather sunny days over land [Pasquill-Gifford dispersion category A (PG-A)]. At the same time, smaller-sized eddies spread the plume about this serpentine centerline. Snapshots of such emission plumes clearly show such looping, but successive snapshots show the locations of the crests and troughs to be constantly shifting as the thermals are blown by the mean wind (Fig. 1a).

When ensemble averaged or time averaged over many convective circulations (to average out these transient loops), there still remains a longer-period, sta-

Corresponding author address: Roland Stull, Department of Earth and Ocean Sciences, The University of British Columbia, 6339 Stores Rd., Vancouver, BC V6T 1Z4, Canada.

E-mail: rstull@eos.ubc.ca tionary, oscillatory pattern of the plume-centerline height versus downwind distance (Fig. 1b), first discovered by Willis and Deardorff (1976, 1978, 1981; hereinafter WD76, WD78, and WD81, respectively). This stationary behavior is evident in time exposures of smoke plumes (Slade 1968), and in time-averaged concentration values measured in the field (Briggs 1993), a laboratory tank (WD76), and large-eddy simulation (LES) models (Lamb 1978).

The reasons for this time-average behavior are the finite $\mathrm{ABL}$ depth, the asymmetry of updrafts versus downdrafts, and mass conservation of air. For a convective $A B L$ heated from the ground, narrow thermals of rapidly rising air reach the top of the ABL, recirculate horizontally, and become broader regions of weaker downdraft. In turn, after the downdraft air reaches the ground, it recirculates horizontally while being heated and then rises again as a narrow updraft. These convective overturnings of air are illustrated in Figs. $2 \mathrm{~b}$ and $2 \mathrm{c}$ with the white arrows. (Note, for a convective ABL circulation driven by radiative cooling at fog top or stratocumulus top, the narrow downdrafts and broader weaker updrafts would lead to opposite effects, not sketched here.) 


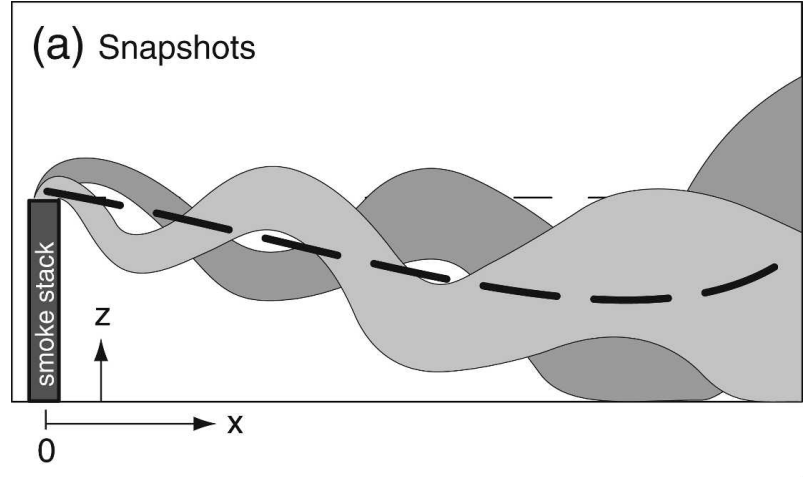

(b) Time average

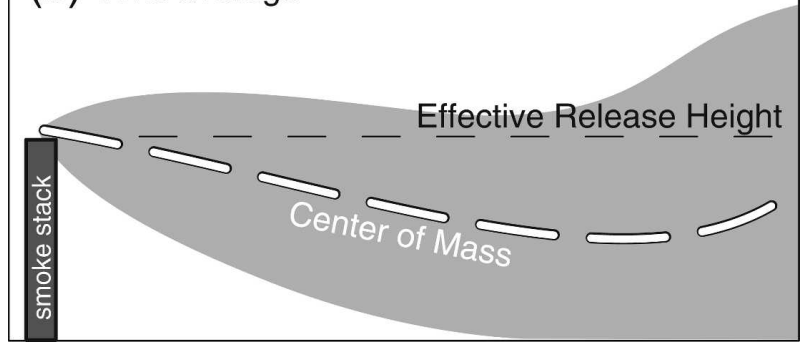

FIG. 1. Illustrations of (a) snapshots of looping smokestack plumes (gray shaded) and (b) their time-averaged spread. Heavy dashed line in both figures is the time-averaged center of mass, and the thin dashed line is the effective release height.

Next, consider what happens when neutrally buoyant smoke is continuously emitted from a stack, as sketched in Fig. 2a. If the wind (from left to right in this idealized sketch) blows with constant speed $\left(\mathrm{m} \mathrm{s}^{-1}\right)$ and advects each convective circulation over a stack having a constant emission rate $\left(\mathrm{kg} \mathrm{s}^{-1}\right)$, then smoke is injected at equal linear emission densities $\left(\mathrm{kg} \mathrm{m}^{-1}\right.$; in the alongwind direction) into the updraft and downdraft portions. However, because the updraft portion is narrower (fewer meters), it receives less total pollutant mass $(\mathrm{kg})$ than does the downdraft. Because of these different masses of pollutant in the updraft and downdraft, we need to track them separately in this illustration. So to help identify the smoke that was initially injected into an updraft, it is shown with the diagonal hatching in Fig. 2.

An odd fact is that these different masses in the updrafts and downdrafts are not what cause the center of mass to deviate from its emission height. For example, in Fig. 2b, although there is less pollutant mass in the updraft, it rises faster away from its emission height than does the pollutant mass in the downdraft, resulting in a center of mass that remains at constant heightnamely, the masses and displacements exactly compensate, as required by the geometry of a closed air-circulation cell.
It is not until the pollutants in either the updraft or downdraft reach the top or bottom of the ABL that the center of mass starts to change. At this point (Fig. 2c), pollutants from the updraft (still being identified with the diagonal hatching) have already recirculated into the downdraft, but the downdraft pollutants (moving more slowly downward) have not reached their boundary yet and are still in the downdraft, too. The net result is that the center of mass moves downward in this example. For a different example (not shown) of a surface emission height, the opposite would happen: air emitted initially into the bottom of the downdraft as it blows over the point source would be almost immediately recirculated horizontally into the updraft portion of the circulation, resulting in the center of mass rising as the convective circulation drifts downwind.

A simplified convective dispersion model (SCDM) was developed by Stull $(1995,2000)$ to approximate the time-averaged, zeroth-order effects of point-source, conservative, pollutant dispersion in a convective ABL. The specific goal was to describe the center of mass of Fig. 2c, not the transient loops of Fig. 2a. The approach was heuristic and empirical, as is normally the case for the equation-fitting step in a similarity-theory dimensional analysis (Stull 1988). He parameterized the longer-wavelength, stationary, oscillatory pattern of the plume-centerline height versus downwind distance with a simple sine wave, phase shifted to account for different source heights, and damped toward $0.5 z_{i}$ (where $z_{i}$ is the average ABL depth) to account for the wellmixed end state of such dispersion. The vertical spread about that oscillatory centerline was given by a truncated Gaussian distribution (normalized to conserve mass), and the horizontal spread was also Gaussian.

The new research presented here also focuses on the time-averaged plume behavior, not on the transient loops. Modifications to the SCDM include a truncated lognormal distribution in the vertical with parameters that are more carefully calibrated against laboratory and numerical-simulation results of crosswind-integrated concentration (CWIC), ground-level CWIC, and vertical plume spread $\sigma_{z}$. The SCDM is further modified to change smoothly its dispersive characteristics as the static stability changes from unstable (free convection; PG-A) toward less unstable (combined free and forced convection; PG-C).

Flat terrain is assumed, and the emitted pollutant is assumed to be passive (nonbuoyant) and conservative (i.e., no deposition or chemical reactions). Relative to the centerline oscillations, the ABL depth $z_{i}$ is assumed to be quasi steady. That is, the ABL-depth oscillation period $(24 \mathrm{~h})$ is assumed to be much longer than a 


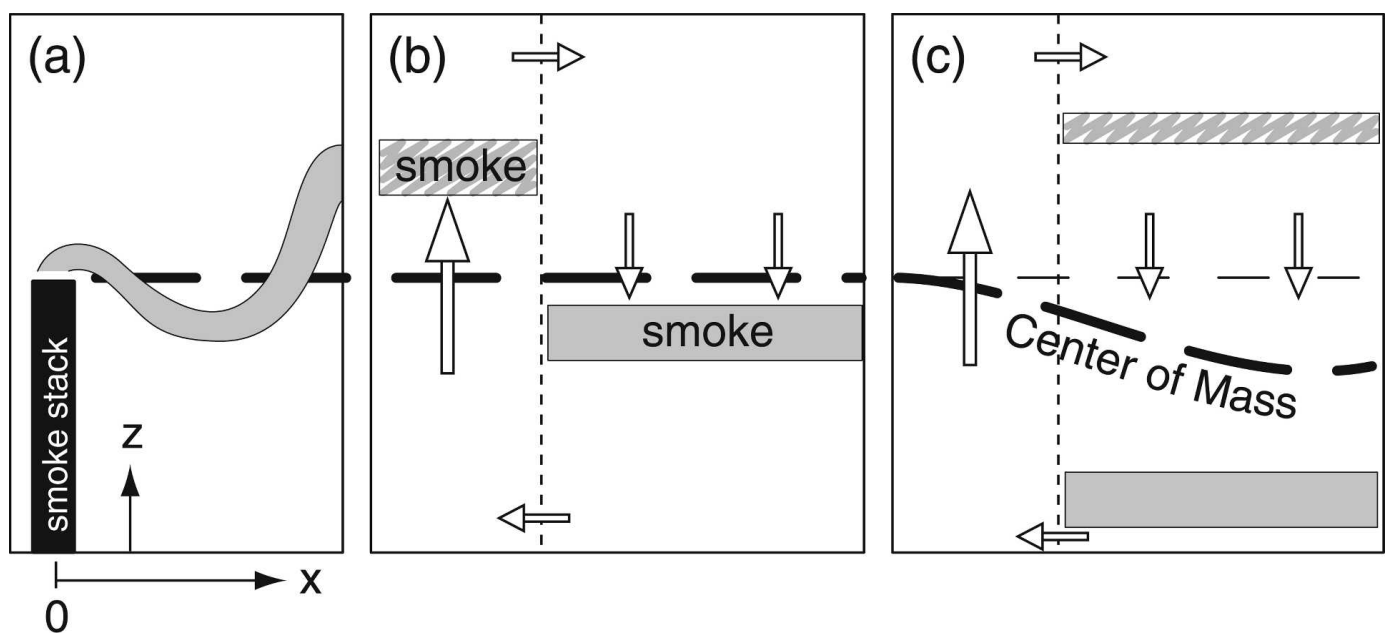

FIG. 2. Sketch showing how an asymmetric convective circulation (white arrows) having strong narrow updraft and broad weaker downdraft affects pollutant center of mass. (a) Idealized constant emission rate from a stack of neutrally buoyant smoke into a constant mean horizontal wind from left to right; (b) movement of smoke in a convective circulation as it advects downwind from the stack; (c)as in (b), only later (farther downwind). Thin horizontal dashed line is effective emission height, and thick dashed line is center of pollutant mass. Vertical dashed line separates idealized updraft from downdraft. The portion of smoke initially emitted into the updraft is indicated with diagonal hatching. The asymmetry of updraft vs downdraft is exaggerated here to aid the interpretation (see text).

convective turnover time of about $t_{*}=z_{i} / w_{*}=15 \mathrm{~min}$, where $w_{*}$ is the Deardorff velocity (defined later).

The SCDM approach is a zeroth-order closure in that it does not parameterize the actual turbulence properties but attempts only to parameterize the net effect of those processes on the mean pollutant state. It is analogous to determining wind by specifying a logarithmic wind profile (a zeroth-order closure from similarity theory), instead of solving the equations of motion for wind while using a first-order $K$-theory closure to approximate the turbulent flux terms.

To test the diagnostic ability of this modified SCDM and to compare it with the dispersion scheme used in the regulatory dispersion model known as the American Meteorological Society and U.S. Environmental Protection Agency (EPA) Regulatory Model, or AERMOD (Cimorelli et al. 2005; Perry et al. 2005, 1994), both models are compared with observations drawn from field studies, tank experiments, and LES. These comparisons include

1) the shape of CWIC isopleths as a function of dimensionless downstream distance and dimensionless height, based on results from the water-tank studies (WD76, WD78, WD81) and the Lamb (1982) LES, 2) predicted ground-level CWIC versus dimensionless downstream distance, based on the Briggs (1985) analytic parameterization and on simulations by Lamb (1978, 1982), WD76, WD78, and Dosio et al. (2003),
3) predicted vertical dispersion parameter $\sigma_{z}$ versus downstream distance, based on parameterizations developed by Briggs (1993) from the Convective Diffusion Observed by Remote Sensors (CONDORS) field program, and on simulations by Hibberd (2000), Luhar et al. (2000), Nieuwstadt (1992), WD76, WD78, and WD81, and

4) changes in shape of CWIC isopleths between buoyancy and shear-driven ABLs, estimated using the LES results of Dosio et al. (2003).

After the defining of key dimensionless variables in section 2, the SCDM is modified in section 3 to account for entrainment and is extended for combined free and forced convection in section 4. The AERMOD dispersion scheme is described in section 5, and both models are compared in section 6. Conclusions and recommendations are in section 7 .

\section{Dimensionless framework}

A Cartesian coordinate system with origin at the smokestack base is defined (Fig. 1a). The $x$ axis points downwind along the average ABL wind direction, with the $y$ axis along the crosswind direction and the $z$ axis in the vertical direction. Dimensionless crosswind and vertical distances are defined as $Y=y / z_{i}$ and $Z=z / z_{i}$. Thus, $Z=1$ is the top of the ABL.

A dimensionless time-averaged centerline height is defined as $Z_{\mathrm{cl}}=z_{\mathrm{cl}} / z_{i}$, where $z_{\mathrm{cl}}$ is the time-averaged 
physical plume-centerline height. Dimensionless emission source height is defined as $Z_{s}=z_{s} / z_{i}$, where $z_{s}$ is effective source height after all downwash and/or plume-rise effects have been included. Lateral pollutant spread, measured as a standard deviation $\sigma_{y}$, is written as a dimensionless variable $\sigma_{y d}=\sigma_{y} / z_{i}$.

With pollutant concentration $c\left(\mathrm{~g} \mathrm{~m}^{-3}\right)$, mean downwind wind speed $U\left(\mathrm{~m} \mathrm{~s}^{-1}\right)$ in the mid-ABL (not at 10-m height), and pollutant emission rate $Q\left(\mathrm{~g} \mathrm{~s}^{-1}\right)$, we form the dimensionless concentration $C=c z_{i}^{2} U / Q$. Last, we define

$$
c_{y}(x, z)=\int_{-\infty}^{\infty} c(x, y, z) d y
$$

as the CWIC $\left(\mathrm{g} \mathrm{m}^{-2}\right)$, with the corresponding dimensionless CWIC defined as $C_{y}=c_{y} z_{i} U / Q$.

For the case of pure free convection (PG-A), the dimensionless downwind distance is

$$
X=x w_{*} /\left(U z_{i}\right)
$$

where

$$
w_{*}=\left[\left(g / T_{v}\right) z_{i}\left(\overline{w^{\prime} \theta_{v}^{\prime}}\right)_{s}\right]^{1 / 3}
$$

is the Deardorff velocity, $g=9.8 \mathrm{~m} \mathrm{~s}^{-2}$ is gravitational acceleration, $T_{v}$ is average absolute virtual temperature in the $\mathrm{ABL}$, and $\left(\overline{w^{\prime} \theta_{v}^{\prime}}\right)_{s}$ is surface kinematic vertical virtual heat flux. The mid-ABL wind speed is often nearly equal to the average wind speed, especially for deep ABLs. Dimensionless distance $X=1$ corresponds to a downstream distance at which the ABL has experienced one complete convective turnover.

When the mean wind speed $U$ in a convective ABL increases, shear production of turbulence in the surface layer contributes increasingly to the overall turbulence kinetic energy and to dispersion (shifting the PasquillGifford dispersion toward B and C). Researchers have suggested a variety of modified velocity scales $w_{m}$ to account for turbulence generated both by convective thermals and by shear at the ground, such as $w_{m}^{2}=$ $w_{*}^{2}+4 u_{*}^{2}$ (Zeman and Tennekes 1977), $w_{m}^{3}=w_{*}^{3}+$ $25 u_{*}^{3}$ (Driedonks 1982), $w_{m}^{3}=w_{*}^{3}+5.8 u_{*}^{3}$ (Deardorff 1983), and $w_{m}^{3}=w_{*}^{3}+5 u_{*}^{3}$ (Tennekes 1973; Moeng and Sullivan 1994; Dosio et al. 2003), where $u_{*}$ is the friction velocity. To allow comparison with the Dosio et al. results, we adopt this last formulation:

$$
w_{m}^{3}=w_{*}^{3}+5 u_{*}^{3} .
$$

The corresponding dimensionless downwind distance (Dosio et al. 2003) is

$$
X_{m}=\frac{w_{m} x}{z_{i} U} .
$$

For pure free convection (i.e., no mean shear), (2) reduces to $w_{m}=w_{*}$ and (3) reduces to $X_{m}=X$.

Neglected in the modified velocity scale of (2) is a third source of turbulence-wind shear $\Delta U$ across the entrainment zone. Fedorovich (2004) showed, using wind-tunnel studies, that this shear can be an important contributor to entrainment for both barotropic and baroclinic ABLs, and Stull (1988) included it in a modified velocity scale $w_{m}^{3}=w_{*}^{3}+30 u_{*}^{3}+0.036(\Delta U)^{3}$. By neglecting this shear, we should not expect the SCDM to work for situations in which such elevated shear dominates the turbulence generation.

Although (2) has sound underpinnings, it is sometimes difficult to use in the field because $u_{*}=\left({\overline{u^{\prime} w^{\prime}}}^{2}+\right.$ $\left.\overline{v^{\prime} w^{\prime}}\right)^{1 / 4}$ and $w_{*}$ are both functions of eddy-correlation (covariance) quantities (Stull 1988), which can be difficult to measure or which require expensive fast-response turbulence sensors such as sonic anemometers/ thermometers. The following approximations are alternatives that use only first-order quantities. For free convection, in place of the Deardorff velocity, one can use the buoyancy velocity scale $w_{B}$ (Stull 1994):

$$
w_{B}=\left[\left(g / T_{v}\right) z_{i} \Delta \theta_{v}\right]^{1 / 2},
$$

where $\Delta \theta_{v}=\theta_{v s k i n}-\theta_{v \mathrm{ML}}$ is the virtual potential temperature difference between the ground surface and the mid-ABL. Note that $\theta_{\text {vskin }}$ can also be difficult to measure in the field. For free convection, the Deardorff velocity is related to the buoyancy velocity by $w_{*} \approx$ $0.08 w_{B}$, where the constant of proportionality is the best estimate from reported field data (Stull 1994).

For forced convection, we estimate the friction velocity from the mean wind speed $U$ in the mid-ABL (using a drag coefficient of $C_{D}=0.01$ ) by $u_{*} \approx 0.1 U$. This value of $C_{D}$ applies to surfaces of medium aerodynamic roughness (cultivated areas with crops of varied heights, and scattered trees or hedgerows) according to the Davenport-Wieringa roughness-length classification (Wallace and Hobbs 2006, their Table 9.2). Thus, mean wind speed in the mid-ABL can be used as a surrogate for shear at the bottom of the ABL, knowing that $U=0$ at the ground.

With the above approximations, an alternative form of (2) is

$$
w_{m}^{3} \approx 0.0005\left(w_{B}^{3}+10 U^{3}\right) .
$$

This expression closely approximates (2) for calm to light winds (when convective turbulence dominates). The equations above can also be combined to show that 


$$
u_{*} / w_{*} \approx 1.25\left(U / w_{B}\right) .
$$

The resulting ratio between dimensionless downwind distance for combined convection $X_{m}$ and for free convection $X$ is

$$
\begin{aligned}
& \frac{X_{m}}{X}=\left[1+5\left(\frac{u_{*}}{w_{*}}\right)^{3}\right]^{1 / 3} \text { or } \\
& \frac{X_{m}}{X}=\left[1+10\left(\frac{U}{w_{B}}\right)^{3}\right]^{1 / 3} .
\end{aligned}
$$

In the limit of pure free convection, $X_{m} / X=1$.

\section{A simple convective dispersion model}

The overall approach is heuristic and empirical. First, a plume-centerline oscillation is designed to match reported observations in amplitude, wavelength, and phase shift with emission height for pure free convection. Second, the CWIC vertical distribution for the case of free convection is described by a simple curve, with the location parameter set to the centerline location, and with spread and shape parameters designed to give best agreement with literature reports of CWIC isopleths and ground-level concentrations. Third, the approach is modified to change as surface-layer wind shear adds increasing amounts of mechanical turbulence to the bottom of a mostly convective $\mathrm{ABL}$.

\section{a. Parameterization of plume-centerline height}

The SCDM parameterizes the time-averaged centerline by a damped oscillation:

$$
Z_{\mathrm{cl} 1}(x)=0.5+\frac{0.5}{1+0.5 X^{2}} \cos \left(2 \pi \frac{X}{\lambda}+\alpha\right),
$$

where dimensionless oscillation wavelength $\lambda$ is given by

$$
\lambda=\left(\frac{X_{m}}{X}\right)^{6} \frac{2 \pi}{\left(1.75-Z_{s}\right)}
$$

and phase shift angle $\alpha$ is

$$
\alpha=\arccos \left(2 Z_{s}-1\right) .
$$

The phase shift ensures that the time-averaged centerline moves initially downward for elevated releases. The centerline parameterization (8) already includes the effects of plume reflection from the ground and from the capping inversion. For large downwind distances, the time-averaged centerline approaches a final height of $Z_{\mathrm{cl}}=0.5$. The wavelength is dependent on dimensionless source height. We initially will focus on free convection, for which $X_{m}=X$.

Because the oscillation in (8) is associated with free
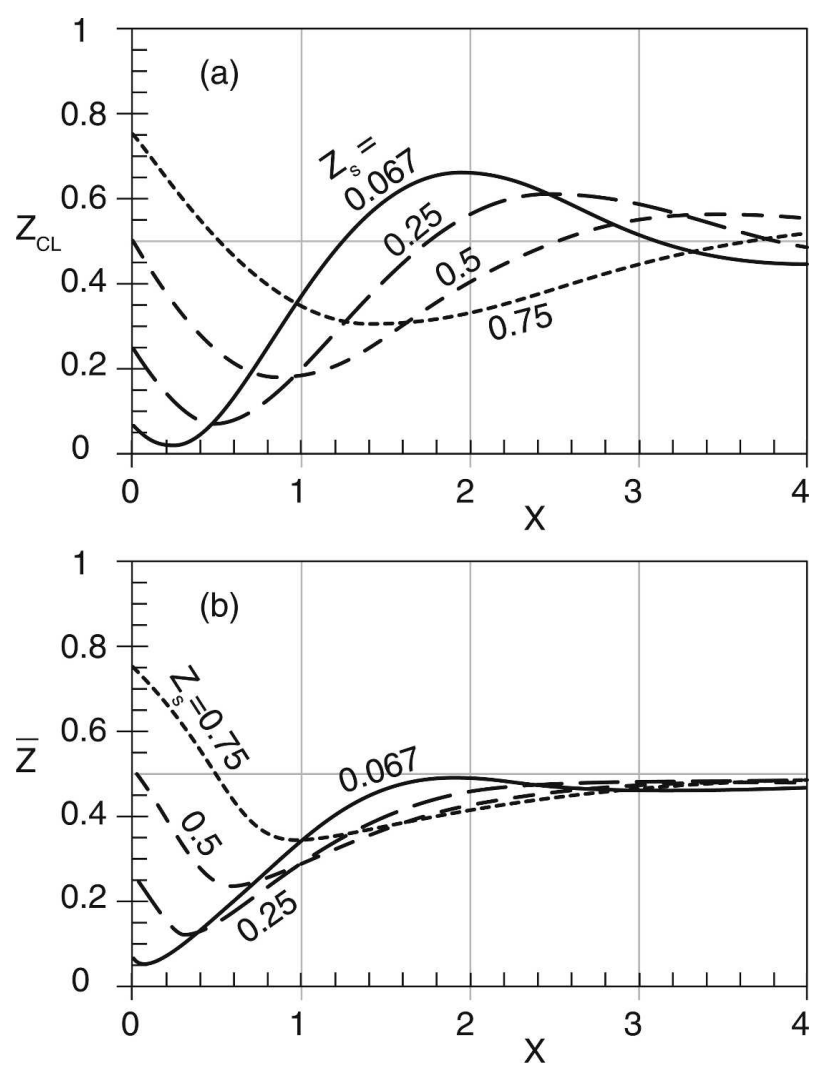

FIG. 3. (a) Plume-centerline dimensionless heights $Z_{\mathrm{CL}}$ as a function of dimensionless downwind distance $X$ and dimensionless release height $Z_{s}$ for pure free convection, based on the SCDM. (b) Same for plume center-of-mass dimensionless height $\bar{Z}$.

convection, (8) is a function of $X$, not $X_{m}$ (except for the wavelength dependence on $X_{m}$ ). The combined effect of using $X$ in the cosine term of (8) while using $X_{m}$ in the wavelength is to cause the time-averaged vertical oscillation to happen more slowly with downwind distance for cases of increasing shear (i.e., for $X_{m}>X$ ). Such behavior was also observed by Dosio et al. (2003), who found that "as the shear-buoyancy ratio increases, the tracer is advected horizontally for a longer time before being lifted up by the thermals."

Figure $3 \mathrm{a}$ shows dimensionless plume-centerline height as a function of dimensionless downstream distance for four dimensionless release heights during pure free convection, using the SCDM parameterization equations in (8)-(10). These curves will be compared with tank and LES simulations in section 6.

\section{b. Parameterization of plume vertical spread}

The original SCDM (Stull 1995, 2000) used a Gaussian distribution to describe the vertical CWIC profile. This profile was centered on the time-averaged oscil- 


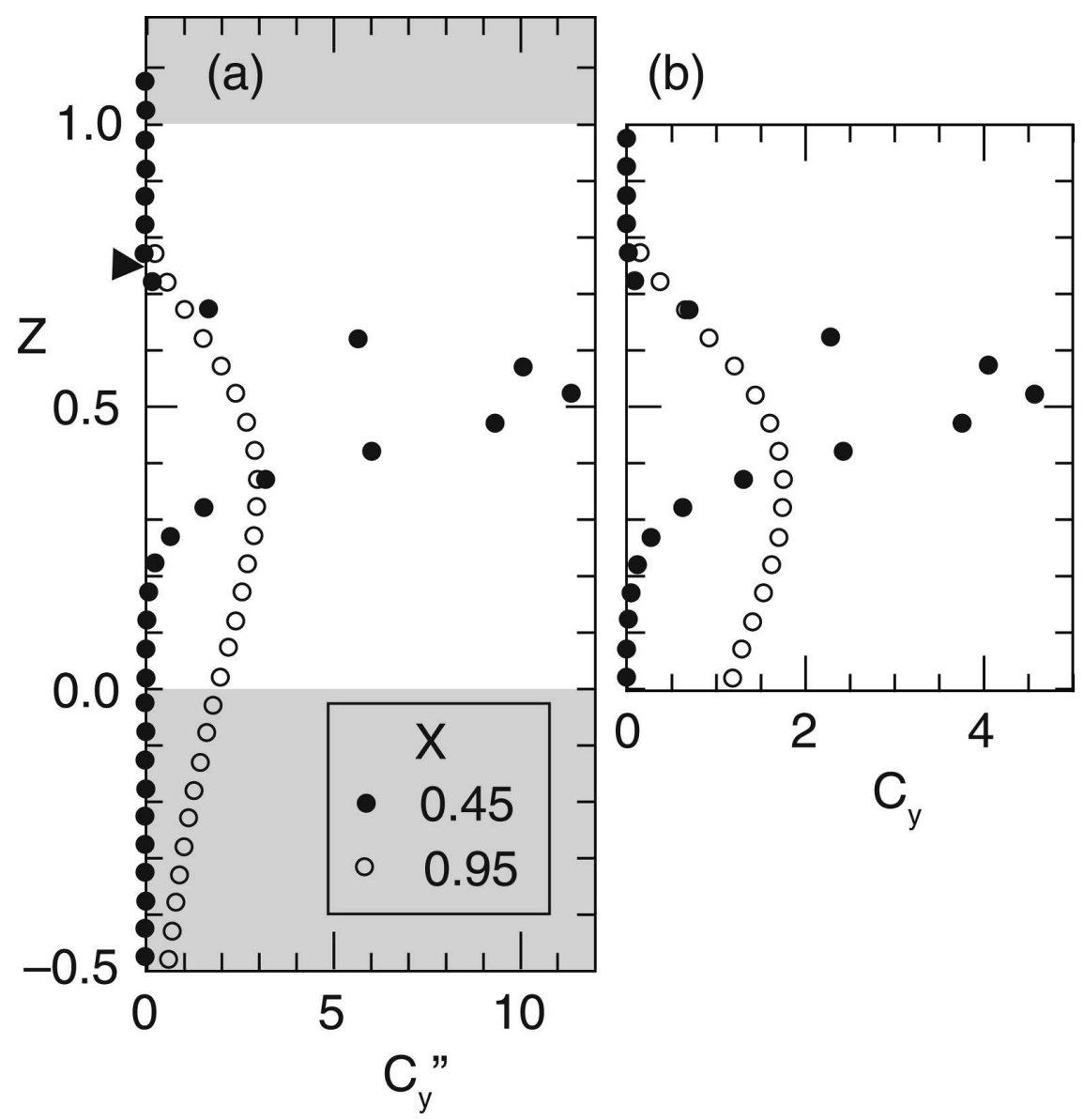

FIG. 4. Illustration of lognormal-distribution normalization method, showing vertical $(Z)$ spread of CWIC from source height $Z_{s}=0.75$ at two downstream distances $X$. Data points show the discretization. (a) Preliminary CWIC values $C_{y}^{\prime \prime}$, where shading shows where the distribution would be truncated to zero. (b) Final normalized CWIC values $C_{y}$, where the areas under both curves are equal, indicating pollutant conservation.

lating plume centerline, had vertical dispersion increasing downwind to mimic the laboratory-tank and numerical simulations, was truncated to be zero outside the range $0<z<z_{i}$, and was then normalized to conserve pollutant mass. The result was visibly appealing and pedagogically useful, but it did not yield the best values for ground-level concentration. Because of the importance of ground-level concentrations in modern air-quality studies, we modify the original SCDM here to yield results that agree better with the observations and simulations reported in the literature.

After experimenting with a variety of distribution functions and spread and shape parameters, we find that the best compromise between simplicity and accuracy is a lognormal distribution function. The CWIC vertical profile is fit using a lognormal distribution that has the tail pointing down and that is truncated to zero above the ABL top and below ground (Fig. 4). The lognormal distribution truncated at the ground gives a result very similar to a Gaussian distribution that is reflected (folded) at the ground. One of the parameters in this lognormal distribution is a function of $Z_{\mathrm{cl}}$ from (8), which enables it to account for thermal turnovers (reflections) at the top and bottom of the ABL. As before, this parameterization is for the time-averaged plume, not the instantaneous plume.

To characterize fully the plume concentrations, conservation of total pollutant mass must still be accounted for. To achieve this, the dimensionless crosswindintegrated concentration $C_{y}$ at any downwind distance $X_{m}$ and any height $Z$ is calculated using three steps. Consider a column of air split into $N$ grid cells, each of equal thickness $\Delta Z=1 / \mathrm{N}$. The center of each grid cell is at height $Z=(k-0.5) \Delta Z$, where $k$ is the cell-height index. For example, if the vertical domain within $Z=$ $0-1$ is discretized into $N=20$ equal-sized layers or cells, 
then the centers of each of those cells is at $Z=0.025$, $0.075,0.125,0.175, \ldots, 0.975$ for $k=1,2,3,4, \ldots, 20$, where each cell has equal dimensionless thickness $\Delta Z=1 / N=0.05$ in this example (see Fig. 4).

First, for any downwind distance $X_{m}$, a preliminary value of CWIC (denoted with primes by $C_{y}^{\prime \prime}$ ) at the center of each grid cell $k$ is calculated assuming a lognormal vertical spread with magnitude truncated to zero outside the ABL:

$$
\begin{aligned}
C_{y}^{\prime \prime}(k)= & \frac{1}{s(1-Z)} \exp \left\{-\frac{[\ln (1-Z)-m]^{2}}{2 s^{2}}\right\} \text { for } \\
& 0 \leq Z \leq 1 \\
= & 0 \text { for } Z<0, Z>1
\end{aligned}
$$

where $m$ is a location parameter and $s$ is a spread parameter, both described below. This preliminary calculation is performed at the $N$ equally spaced heights (grid-cell centers in a single column) between the ground and the top of the ABL (Fig. 4a).

The vertical spread parameter increases with downwind distance $X\left(\right.$ not $\left.X_{m}\right)$ by

$$
s=0.5 X^{r},
$$

where, for this SCDM,

$$
r=1.25-0.25 \exp \left[-0.5\left(Z_{s} / 0.1\right)^{4}\right] .
$$

This is an S-shaped function that varies from $r=1.0$ at $Z_{s}=0$ to $r=1.25$ at $Z_{s}=0.2$ and then is constant $(r=$ $1.25)$ to the top of the ABL. For example, at $Z_{s}=0.067$ it has a value of $r=1.02$. This slight decrease of spreadrate exponent only close to the surface gives the best fit to the empirical data and suggests that the vertical dispersive effects of large convective circulations are reduced slightly near the ground, perhaps by limiting the spectrum of possible vertical eddy sizes there.

The fact that $X$ provides a better fit to the observations than $X_{m}$ in (12) suggests that it is the convectively caused large-eddy looping of the instantaneous plume that is the greatest cause of spread $s$ of the timeaveraged plume. That is, the extra shear-generated small-eddy turbulence in $X_{m}$ that is not in $X$ might play a minor role in the time-averaged spread.

The vertical location parameter is found from

$$
m=s^{2}+\ln \left(1-Z_{\mathrm{CL}}\right)
$$

and is a function of $X$ and $X_{m}$ because $Z_{\mathrm{CL}}$ and $s$ are functions of $X$ and $\lambda$ in $Z_{\mathrm{CL}}$ is a function of $X_{m}$.

The second part of this three-step process is, for any downwind distance $X_{m}$, to compute the average $\left(\overline{C_{y}^{\prime \prime}}\right)$ of the preliminary CWIC values over all the grid cells in the vertical direction that are within $0 \leq \mathrm{Z} \leq 1$ :

$$
\overline{C_{y}^{\prime \prime}}=\frac{1}{N} \sum_{k=1}^{N} C_{y}^{\prime \prime}(k) .
$$

This is needed because the lognormal distribution (11) is truncated to zero outside the $\mathrm{ABL}$, and must be renormalized to conserve pollutant mass. For example, at $X=0.45$ in Fig. 4 a $\overline{C_{y}^{\prime \prime}}=2.51$ and at $X=0.95$ it is $\overline{C_{y}^{\prime \prime}}=1.71$.

The last step is to divide the preliminary CWIC value from (11) at any grid-cell height $Z$ (i.e., for any height index $k$ at the fixed $X_{m}$ ) by the average from (15), to find the CWIC:

$$
C_{y}(k)=C_{y}^{\prime \prime}(k) \overline{C_{y}^{\prime \prime}} .
$$

This procedure guarantees that the mass of pollutants is conserved downstream. Because of the normalization procedure of (16), (11)-(16) must be solved at all heights in a column (i.e., solve for all $Z$ at a fixed $X_{m}$ ), even if $C_{y}$ at only one height is needed. For example, Fig. $4 \mathrm{~b}$ shows the CWIC profiles after being divided by their respective averages.

The simple approach taken here has limitations, which can be understood by comparing real atmospheric processes with the SCDM. In the real atmosphere, shear-generated turbulence in the surface layer and across the entrainment zone (Stull 1976) can cause two kinds of change. One is an increase in small-eddy turbulence, which would tend to homogenize the CWIC vertical profile in those two regions. Counteracting that effect at the entrainment zone is increased entrainment of cleaner air from the free atmosphere, which would tend to dilute the CWIC concentration there. As a zeroth-order dispersion closure model, the SCDM does not include equations for these two processes, but instead attempts to approximate their "typical" net effects. We mimic the homogenization effect by allowing the raw CWIC vertical profile to spread below ground and above the ABL top. The normalization procedure of (15) and (16) effectively chops off those unrealistic portions of the spread and adds the missing mass back uniformly into the whole ABL. By not allowing loss of pollutants upward through the entrainment zone, this approach is limited to the following situations: passive nonbuoyant emissions, no anabatic venting such as over ridge tops, and no cloud venting.

A fortuitous by-product of using the lognormal distribution (11) to improve ground-level concentration is that the CWIC now also mimics the entrainmentdilution effect by allowing more dilution of concentration at the ABL top. This has a desirable attribute that 
after many convective turnovers and thorough vertical mixing, the final center of mass should not approach $0.5 z_{i}$ but should be slightly below it, to account for continual entrainment of cleaner air into the ABL top. Because the SCDM is fixed and does not include parameters that vary with shear aloft, and because it only indirectly includes surface-layer shear by means of the mean wind speed in the ABL, it is not likely to give good results for ABLs (both baroclinic and barotropic) that have substantial shear across the entrainment zone.

\section{c. Cross-wind integrated concentration}

Equations (11)-(16) can be solved for each downwind distance $X_{m}$, and then the array of results $\left(C_{y}\right.$ values as a function of $X_{m}$ and $Z$ ) can be contoured and plotted. Figure 5 shows the isopleths of CWIC calculated with the SCDM for four different release heights, using the plume-centerline and plume-spread equations given above and assuming pure free convection $\left(X_{m}=\right.$ $X)$. These concentrations are compared with the WD78 and WD81 tank observations and the Lamb (1982) LES simulations shown in Fig. 6. In general, the SCDM isopleths agree closely with the tank and LES studies, for this pure free-convection scenario. Fedorovich and Thäter (2002) found similar results using a convectively stratified wind tunnel.

In the Willis and Deardorff tank experiments, the emission "smokestack" was towed through the tank, which mimicked the mean-wind effects of emission dilution and space-time coupling through Taylor's hypothesis but not the corresponding shear generation of turbulence at the top and bottom of the ABL. Thus, we would expect the tank results to have too little smalleddy dispersion in the surface layer and too little entrainment dilution at the ABL top. To compensate for this effect, the SCDM is designed to produce slightly larger near-source ground-level concentrations than those found by Willis and Deardorff, as is discussed in more detail in section 6 .

\section{d. Plume center of mass}

Knowing the vertical distribution of CWIC, one can find the plume center of mass $\bar{Z}$ at any downwind distance $X_{m}$ by

$$
\bar{Z}=\frac{\sum_{k} Z(k) C_{y}(k)}{\sum_{k} C_{y}(k)} .
$$

For pure free convection, the center of mass of the time-averaged plume as diagnosed from the SCDM is

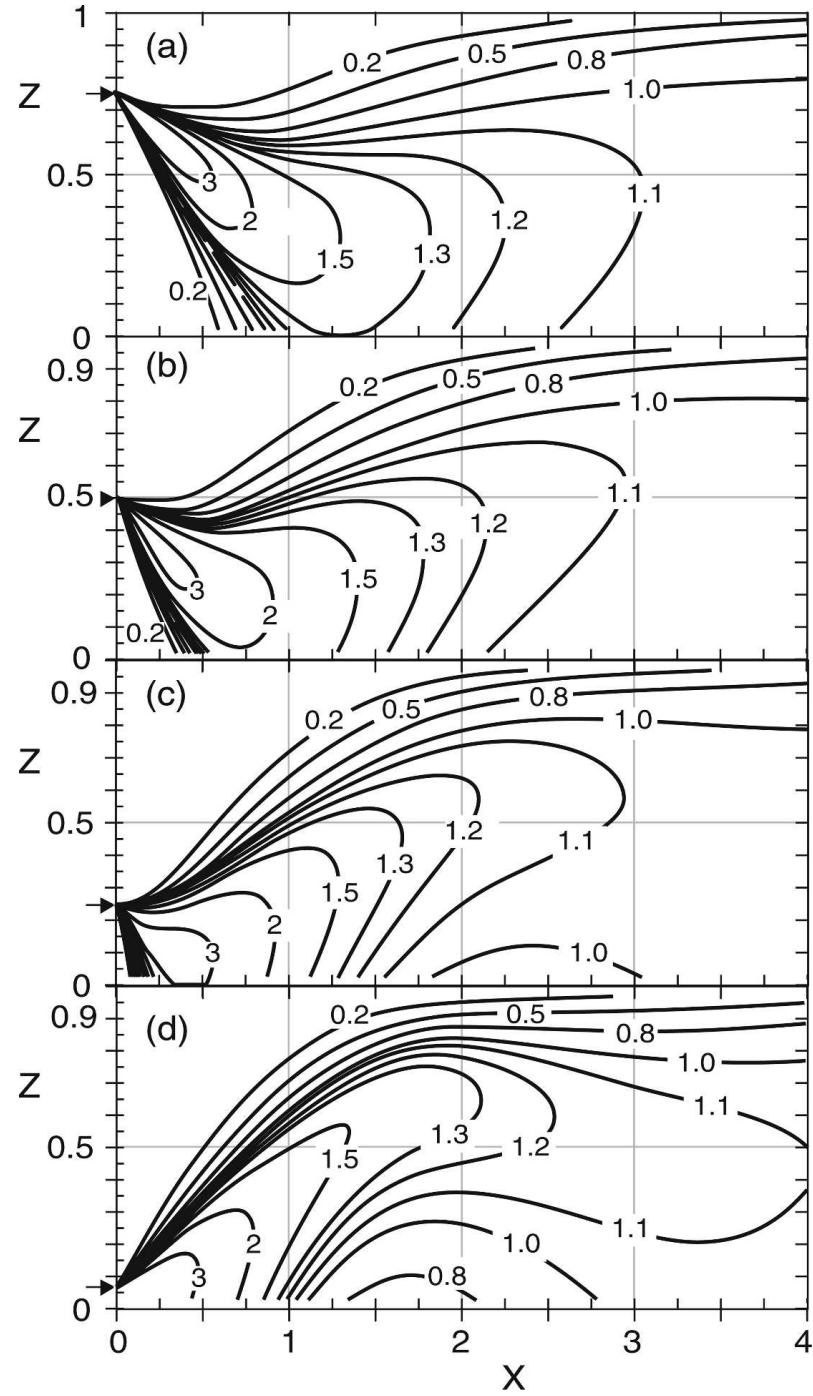

FIG. 5. Isopleths of dimensionless crosswind-integrated concentration $C_{y}$ vs dimensionless height $Z$ and dimensionless downwind distance $X$ in a pure convective mixed layer, found using SCDM. Dimensionless release heights $Z_{s}$ are (a) 0.75, (b) 0.5, (c) 0.25, and (d) 0.067 , as indicated by the small arrow on the ordinate.

shown in Fig. $3 b$ for the same four source heights as in Fig. 3a.

\section{e. Concentration}

Knowing CWIC and assuming that time-averaged crosswind dispersion is Gaussian, one can find the dimensionless concentration $C$ at any dimensionless location $\left(X_{m}, Y, Z\right)$ from

$$
C=\frac{C_{y}}{(2 \pi)^{1 / 2} \sigma_{y d}} \exp \left[-0.5\left(\frac{Y}{\sigma_{y d}}\right)^{2}\right]
$$

where the dimensionless lateral spread is 


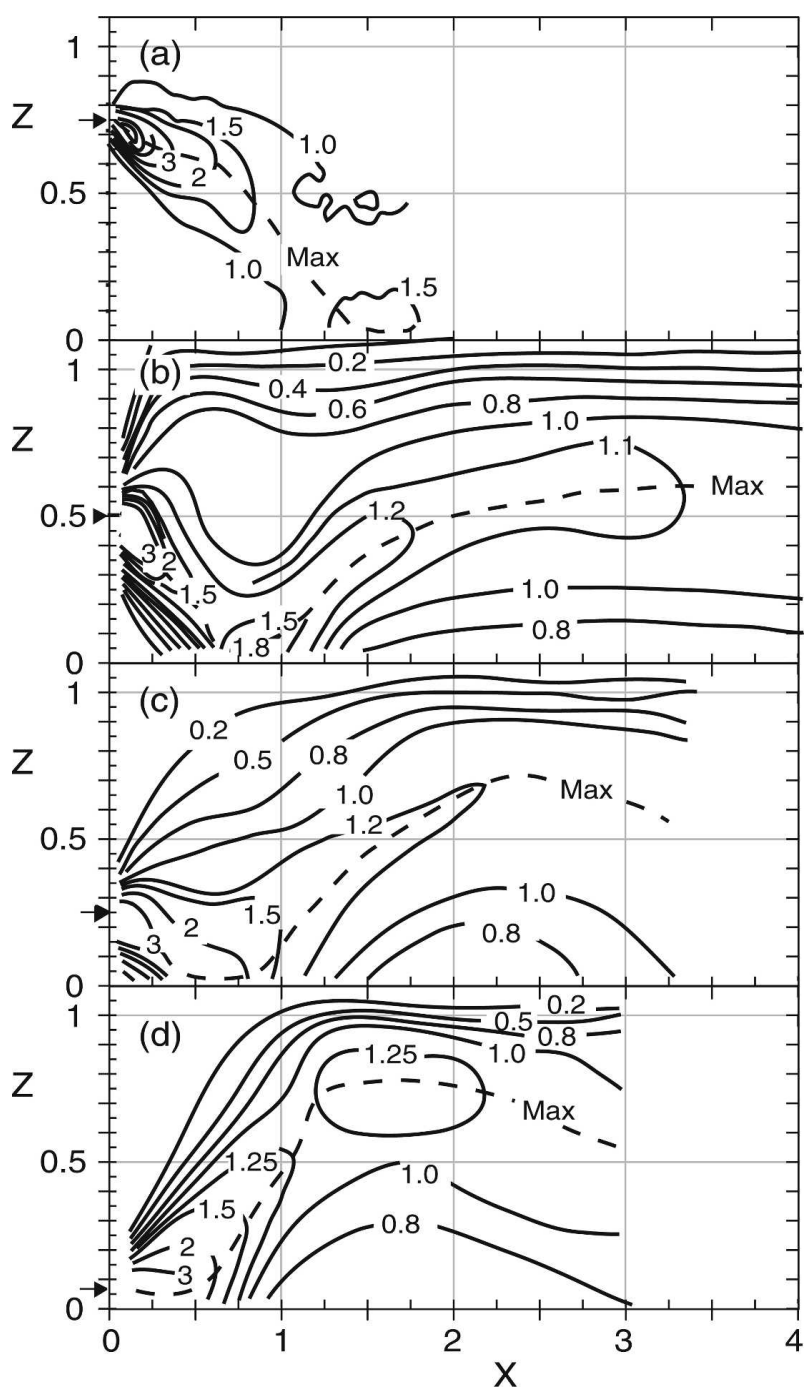

FIG. 6. Isopleths of dimensionless crosswind-integrated concentration similar to Fig. 5, but from the laboratory and numerical simulations of WD78, WD81, and Lamb (1982).

$$
\sigma_{y d}=0.5 X_{m}
$$

Physical concentration $c$ can then be found from (18) using the definition of dimensionless concentration $C$ :

$$
c=C Q /\left(z_{i}^{2} U\right)
$$

This parameterization approach gives no information about concentration fluctuations $\frac{c^{\prime 2}}{\text {. }}$.

\section{f. Other statistics}

If desired, the vertical spread (i.e., standard deviation $\sigma_{z}$ ) at each downstream location can be calculated from the SCDM output using
TABLE 1. Experiment identification (ID) for different mechanical and buoyant forcings, where $u_{*}$ is friction velocity, $w_{*}$ is Deardorff velocity, $X$ is dimensionless length scale for pure free convection, $X_{m}$ is dimensionless length scale for combined free and forced convection, $U$ is approximate mean wind speed in midmixed layer, and $w_{B}$ is buoyancy velocity scale.

\begin{tabular}{lccclccl}
\hline \hline & $\begin{array}{c}u_{*} \\
\left(\mathrm{~m} \mathrm{~s}^{-1}\right)\end{array}$ & $\begin{array}{c}w_{*} \\
\left(\mathrm{~m} \mathrm{~s}^{-1}\right)\end{array}$ & $u_{*} / w_{*}$ & $X_{m} / X$ & $\begin{array}{c}U \\
\left(\mathrm{~m} \mathrm{~s}^{-1}\right)\end{array}$ & $\begin{array}{c}w_{B} \\
\left(\mathrm{~m} \mathrm{~s}^{-1}\right)\end{array}$ & $U / w_{B}$ \\
\hline B1 & 0.05 & 1.6 & 0.031 & 1.0 & 0.5 & 20 & 0.025 \\
B5 & 0.1 & 0.8 & 0.125 & 1.003 & 1 & 10 & 0.1 \\
SB & 0.5 & 1.6 & 0.313 & 1.05 & 5 & 20 & 0.25 \\
S & 1 & 2.4 & 0.417 & 1.11 & 10 & 30 & 0.333 \\
NN & 1.5 & 2.4 & 0.625 & 1.31 & 15 & 30 & 0.5 \\
\hline
\end{tabular}

$$
\sigma_{z}(X)=\left\{\frac{\sum[Z-\bar{Z}(X)]^{2} \mathrm{CWIC}(X, Z) \Delta z}{\sum \mathrm{CWIC}(X, Z) \Delta z}\right\}^{1 / 2}
$$

where the sums are over all of the vertical levels.

The coefficient of skewness of pollutant altitude is defined as

$$
\text { Skewness }=\frac{\overline{Z^{\prime 3}}}{\left(\overline{Z^{\prime 2}}\right)^{3 / 2}},
$$

where $\overline{Z^{\prime 2}}=\sigma_{z}^{2}$ and

$$
\overline{Z^{\prime 3}}(X)=\frac{\sum[Z-\bar{Z}(X)]^{3} \mathrm{CWIC}(X, Z) \Delta z}{\sum \mathrm{CWIC}(X, Z) \Delta z} .
$$

\section{Further SCDM modifications to include both buoyant and shear forcings}

\section{a. Experiment design}

Dosio et al. (2003) performed an extensive series of LES experiments to estimate how dispersion changed as the turbulence varied from free convection toward forced convection. Following their approach, we study five scenarios in which turbulence is produced by a range of relative contributions of buoyant and shear forcings. These scenarios are summarized in Table 1, using the same experiment designations (ID) as were used by Dosio et al. (2003).

Experiment B1 is for a case with almost pure free convection, with a large buoyancy and very small surface-layer wind shear. Experiment B5 is another case with almost pure free convection but with slightly larger shear and smaller buoyancy. Both B1 and B5 correspond to Pasquil-Gifford dispersion category $A$ (PG-A). Because the first two experiments (B1 and B5) 
yield almost identical free-convection results, we sometimes treat them together in a discussion of B1.

Experiment SB is a buoyant case with some surfacelayer shear, in the PG-B to PG-C range. Experiments S and $\mathrm{NN}$ add increasingly strong surface-layer shear to the strong buoyancy, giving PG-C. None of these experiments is intended to mimic pure forced convection (PG-D), for which traditional Gaussian plume models perform very well (Arya 1999).

\section{b. Variation of convective dispersion with increasing mechanical production}

When (7) is used in (9) to increase the wavelength of the plume centerlines, the resulting SCDM includes the effects of mechanically generated turbulence in an ABL still dominated by buoyancy. Figure 7 a shows variation of the plume-centerline height for the range of increasing mechanical turbulence, for near-surface emissions at $Z_{s}=0.067$, as modeled with the SCDM. When the lognormal vertical distribution of concentration [(11)-(16)] is used with these centerlines, the resulting SCDM center-of-mass curves are shown in Fig. $7 \mathrm{~b}$ (where the B5 curve is almost identical to the B1 curve and is not plotted). The SCDM center of mass approaches a final height of $Z=0.46$, mimicking entrainment, which differs from the final height of 0.5 simulated by Dosio et al. (Fig. 7c) using LES. Also, the spread of the center-of-mass curves in Fig. $7 \mathrm{~b}$ is less than that found by Dosio et al., and their LES centerof-mass curves approach their limiting value farther downwind.

The corresponding curves for mid-ABL emissions $\left(Z_{s}=0.5\right)$ are plotted in Fig. 8. Again, the magnitude of the time-averaged centerline oscillation (Fig. 8a) decreases with increasing shear turbulence (consistent with the LES results), and the center of mass (Fig. 8b) shows more spread between curves than those found by Dosio et al. (Fig. 8c) using LES.

\section{AERMOD}

To compare the SCDM with AERMOD (Cimorelli et al. 2005; Perry et al. 2005, 1994), we start with the source code for AERMOD (version 99351) that was available from EPA's Support Center for Regulatory Atmospheric Modeling Web site (http://www.epa.gov/ $\mathrm{ttn} / \mathrm{scram})$. We then modify the code to create a program (AERMOD-M) capable of outputting receptor concentrations and other variables needed to calculate nondimensional concentrations and distances. To run the program for a variety of receptor and source heights, a shell script is used to create the necessary input files, launch the AERMOD-M executable, and

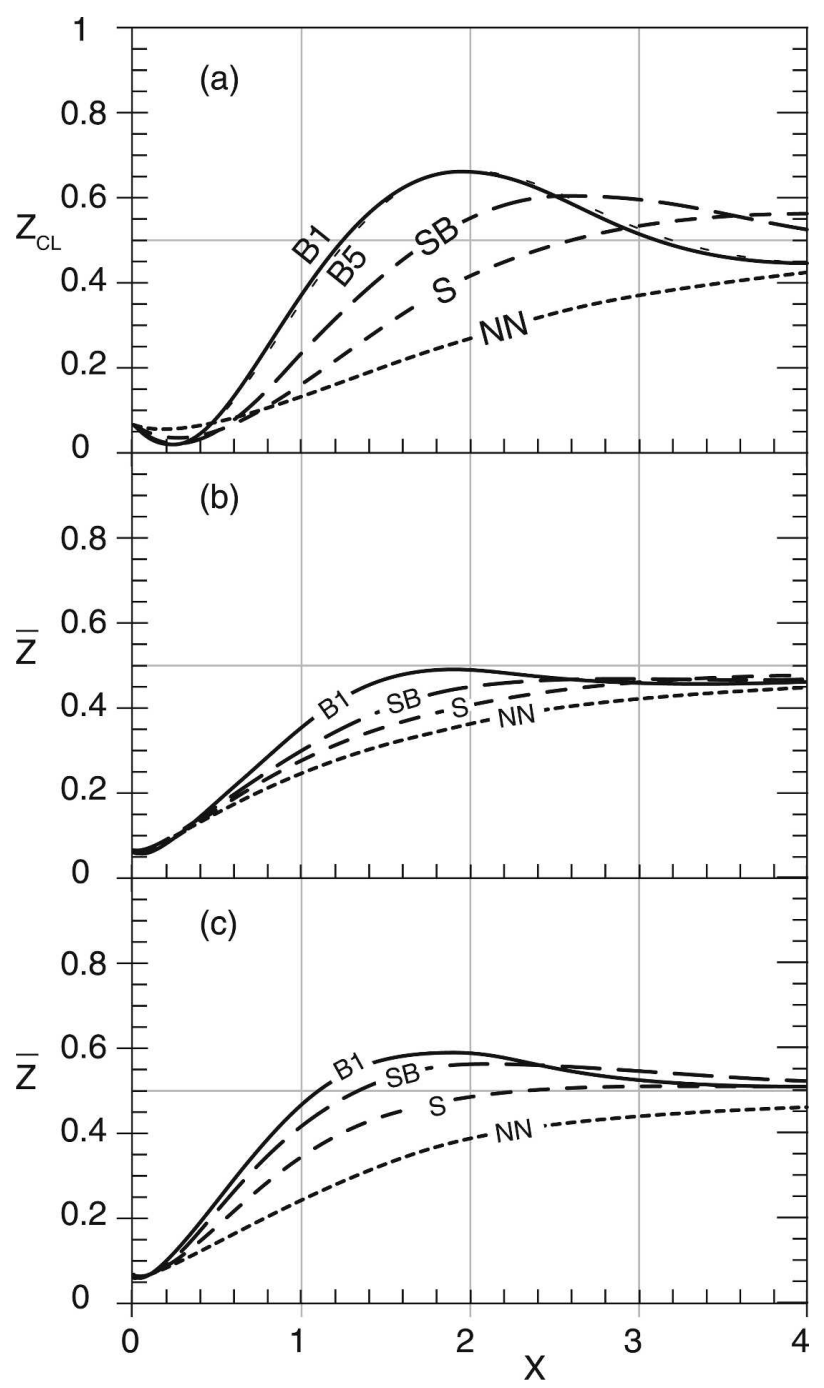

FIG. 7. Downwind $X$ evolution of (a) centerline height and (b) center of mass from the simple convective dispersion model, for a plume released at $Z_{s}=0.067$. The different curves are for different amounts of mechanical turbulence added to a predominantly convective mixed layer (see Table 1) from almost pure free convection B1 to significant mechanical production $\mathrm{NN}$ of turbulence. (c) Same as (b), but from Dosio et al. (2003).

manage the model output. Postprocessing of the output is handled by a separate program.

\section{a. Model setup}

AERMOD-M is set up to simulate the dispersion of a nonbuoyant passive pollutant over flat terrain, with no stack tip downwash and no deposition or emission half-life. Concentrations are calculated throughout a receptor network located downwind of the source and on only one side of the centerline, by assuming crosswind symmetry. The network has $101 \times 201$ receptors in the downwind and crosswind directions, with grid spacings of 50 and $30 \mathrm{~m}$, respectively. The network has 


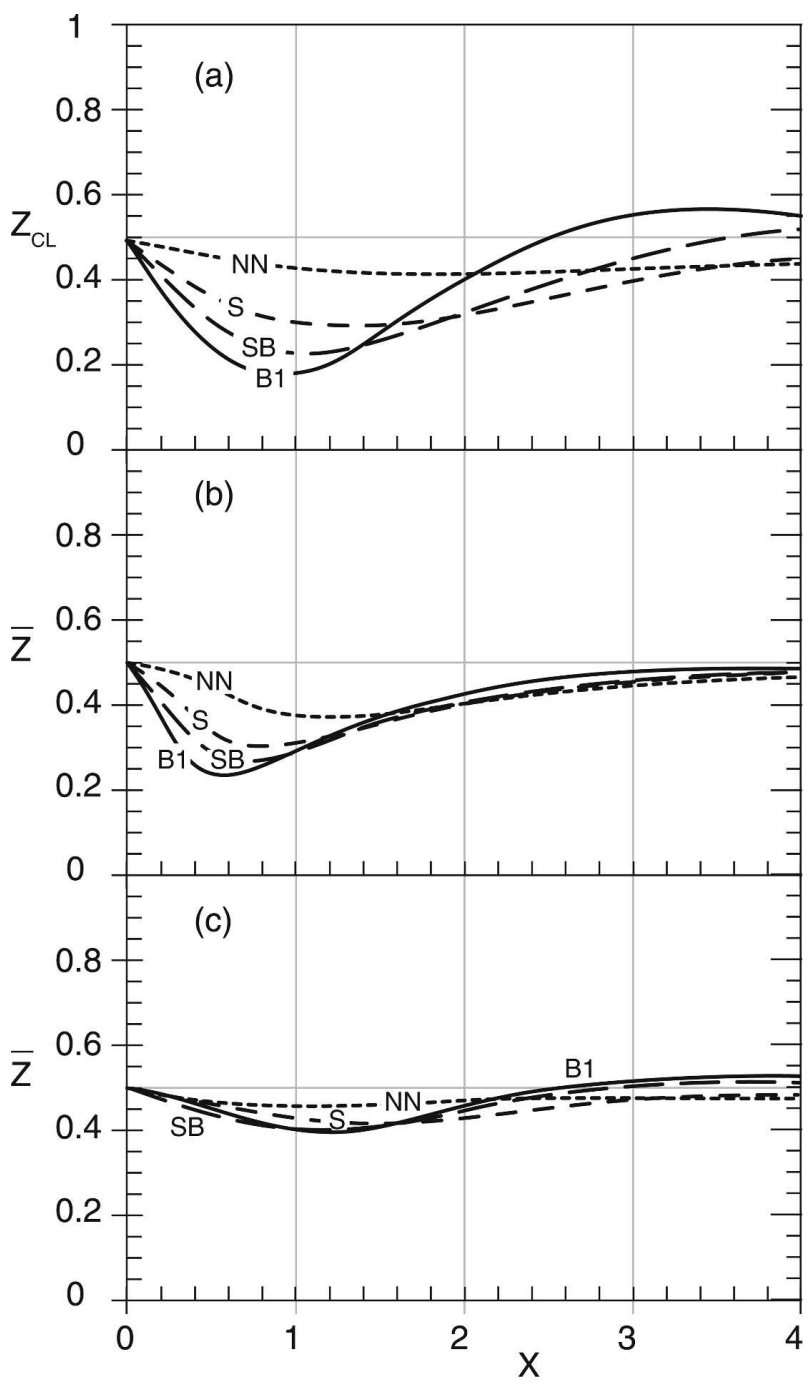

FIG. 8. Same as Fig. 7, but for a plume released at $Z_{s}=0.5$.

a maximum downwind distance of $x=5000 \mathrm{~m}$. Because AERMOD includes the effect of increasing horizontal wind speed with height, the nondimensional distance $X$ is a function of $z$. As a result, the maximum downwind dimensionless distance of the network ranges between $X=4.3$ (at ground level) and $X=4.0$ (at ABL top).

Stack source heights of $33.5,125,250$, and $375 \mathrm{~m}$, relative to a specified $\mathrm{ABL}$ depth of $z_{i}=500 \mathrm{~m}$, are used to simulate a range of dimensionless release heights similar to those obtained in the tank and LES studies. For each source height, the program is run 51 times with the network receptor heights varying from 0 $\mathrm{m}$ (ground level) to $500 \mathrm{~m}$ (top of the ABL) in 10-m increments. An arbitrary source strength of $500 \mathrm{~g} \mathrm{~s}^{-1}$ is used for all simulations.

For meteorological input, AERMOD requires data from "AERMET," its meteorological preprocessor.
TABLE 2. Input variables for AERMOD-M run.

\begin{tabular}{|c|c|}
\hline Surface variables & Value \\
\hline Year & 1999 \\
\hline Month & 6 \\
\hline Day & 21 \\
\hline Yearday $(\mathrm{JD})^{*}$ & 172 \\
\hline Hour & 12 \\
\hline Heat flux $H\left(\mathrm{~W} \mathrm{~m}^{-2}\right)$ & 300 \\
\hline Friction velocity $u_{*}\left(\mathrm{~m} \mathrm{~s}^{-1}\right)$ & 0.31 \\
\hline Deardorff velocity $w_{*}\left(\mathrm{~m} \mathrm{~s}^{-1}\right)$ & 1.59 \\
\hline $\begin{array}{l}\text { Vertical potential temperature gradient above } \\
z_{i}\left(\mathrm{~K} \mathrm{~km}^{-1}\right)\end{array}$ & 0.005 \\
\hline (Convective) mixed-layer depth $z_{i}(\mathrm{~m})$ & 500 \\
\hline (Mechanical) boundary layer depth $z_{i}(\mathrm{~m})$ & 35 \\
\hline Obukhov length $L(\mathrm{~m})$ & -9.55 \\
\hline Roughness length $z_{o}(\mathrm{~m})$ & 0.10 \\
\hline Bowen ratio & 1.3 \\
\hline Albedo & 0.2 \\
\hline Mean wind speed $U\left(\mathrm{~m} \mathrm{~s}^{-1}\right)$ & 2.75 \\
\hline Wind direction $\left(^{\circ}\right)$ & 270 \\
\hline Reference height for wind speed and direction $(\mathrm{m})$ & 10.0 \\
\hline Temperature $(\mathrm{K})$ & 300 \\
\hline Reference height for temperature (m) & 10.0 \\
\hline Profile variables & Value \\
\hline Year & 1999 \\
\hline Month & 6 \\
\hline Day & 21 \\
\hline Hour & 12 \\
\hline Height of measurement (m) & 250 \\
\hline Flag & 1 \\
\hline Wind direction $\left(^{\circ}\right)$ & 270 \\
\hline Wind speed $U\left(\mathrm{~m} \mathrm{~s}^{-1}\right)$ & 3.6 \\
\hline Temperature $\left({ }^{\circ} \mathrm{C}\right)$ & 24.5 \\
\hline Std dev wind direction $\sigma_{\theta}\left({ }^{\circ}\right)$ & 17.7 \\
\hline Std dev vertical velocity $\sigma_{w}\left(\mathrm{~m} \mathrm{~s}^{-1}\right)$ & 1.0 \\
\hline
\end{tabular}

This program takes station observations like wind speed, wind direction, and cloud cover and calculates the appropriate micrometeorological variables required for dispersion calculations. We eliminate the need for AERMET by supplying AERMOD-M with meteorological data prepared manually using a set of micrometeorological variables appropriate to convective ABL conditions (see appendix). These variables are passed to AERMOD-M using two files-one that describes surface conditions and one that describes the vertical profile of the ABL-as summarized in Table 2.

\section{b. Crosswind-integrated concentrations, plume centerline, and vertical spread}

The CWIC is calculated at each downstream location and at every receptor height. First, the dimensional total crosswind concentration $c_{y}$ is calculated by numerically integrating the 201 crosswind AERMOD-M- 
calculated concentrations. This is then made nondimensional using $z_{i}(=500 \mathrm{~m}), Q\left(=500 \mathrm{~g} \mathrm{~s}^{-1}\right)$, and the effective horizontal pollutant-plume velocity (UEFFD) appropriate to each vertical level. The UEFFD is calculated internally by AERMOD and is output to file at each receptor location.

Because of the dependence of dimensionless downstream distance $X$ on height, plume centerline and vertical spread were calculated with respect to dimensional downstream distance $x$. First, at each downstream distance, the dimensional plume centerline $z_{\mathrm{CL}}$ was calculated in a manner identical to the nondimensional plume-centerline formulation given in (17). Next, AERMOD-M vertical plume spread was calculated using (21) but with CWIC replaced by dimensional $c_{y}$ as defined in section 2 . The resulting vertical dimensional plume spread was then made nondimensional by scaling with the ABL height. To determine the dimensionless downstream distance appropriate for each $\sigma_{z}(x) / z_{i}$, the UEFFD at the plume centerline was used to calculate $X$.

\section{Comparison of AERMOD-M and SCDM for free convection}

\section{a. Crosswind-integrated concentration}

CWIC isopleths calculated from AERMOD are shown in Fig. 9 for free convection. The isopleths do not show much structure past $X=2$, suggesting that the model mixes the plume more quickly than the tank studies and LES results. For elevated releases, there is little evidence that the time-averaged plume reflects upward from the ground after descending.

Isopleths from AERMOD show high concentrations at the top of the ABL for $X<2$. This result likely arises from the plume lofting that has been incorporated into AERMOD, through the superposition of an indirect plume source located at $2 z_{i}$ (Cimorelli et al. 2005).

\section{b. Ground-level values of CWIC}

Plots showing expected ground-level CWIC versus downstream distance for both AERMOD and SCDM are shown in Fig. 10. The Briggs (1985) parameterization has also been included, along with tank and LES results. Both AERMOD and SCDM give similar results for the near-surface release. For the elevated releases $\left(Z_{s}=0.75\right.$ and 0.5$)$, AERMOD noticeably underestimates the peak ground-level CWIC for $X<2$.

Perry et al. (2005) have compared AERMOD with results from 17 different field studies encompassing a range of atmospheric conditions, land-use types, and terrains. Their results focus on model comparisons of maximum ground-level concentrations, using several

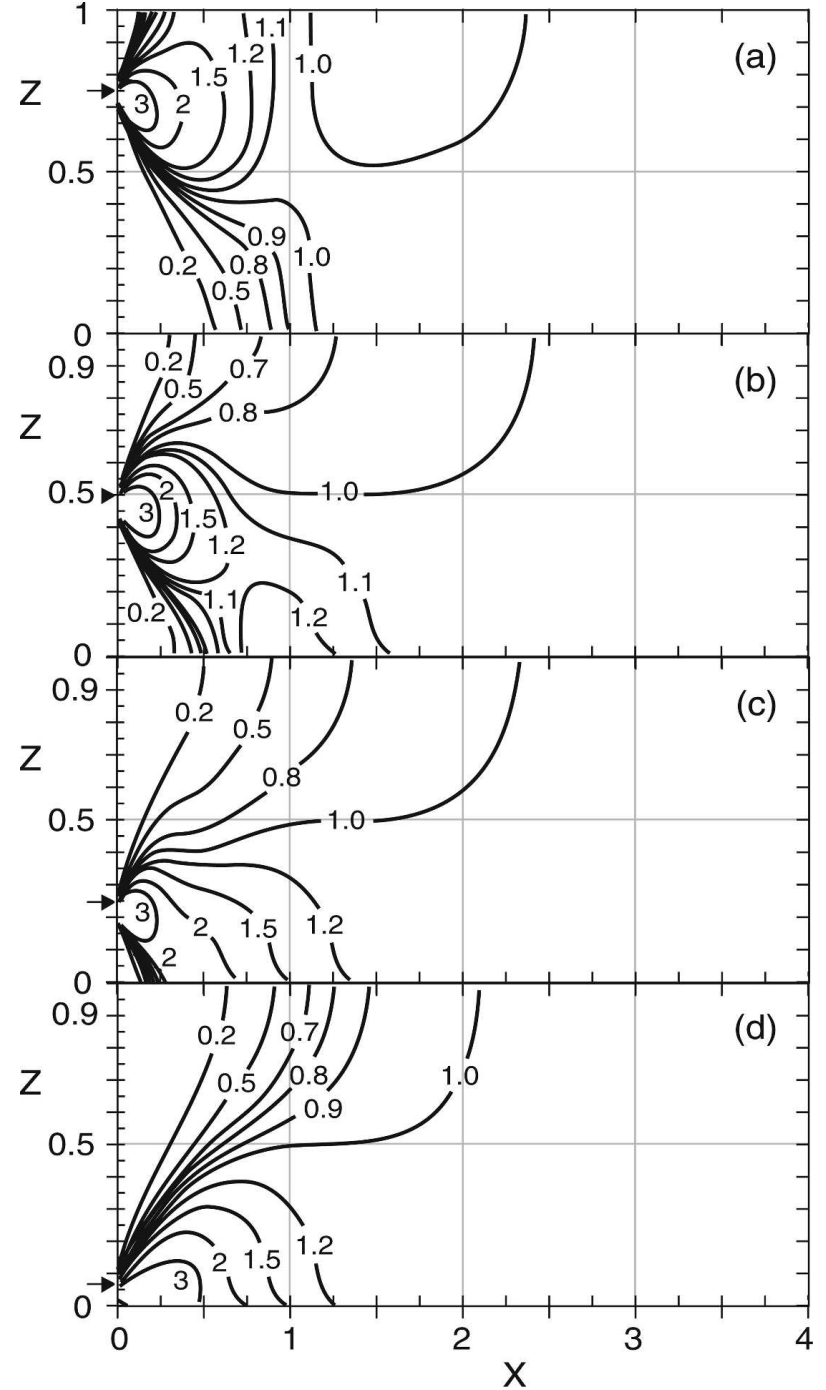

FIG. 9. CWIC isopleths similar to Fig. 5, but from AERMOD for nearly pure free convection.

statistical measures of agreement, and not on the agreement between AERMOD and tank studies using nondimensional variables. However, comparisons of field studies performed over flat terrain in rural locations show AERMOD underpredicting peak ground-level concentration for both elevated and surface releases, consistent with our findings.

\section{c. Vertical dispersion}

Figures $11 \mathrm{a}$ and $11 \mathrm{~b}$ show plots of the vertical dispersion parameter $\sigma_{z}$ versus dimensionless downstream distance for the SCDM and AERMOD for free convection. Also shown are three empirical relationships for $\sigma_{z} / z_{i}$.

Based on the CONDORS field-experiment data, Briggs (1993) suggests 

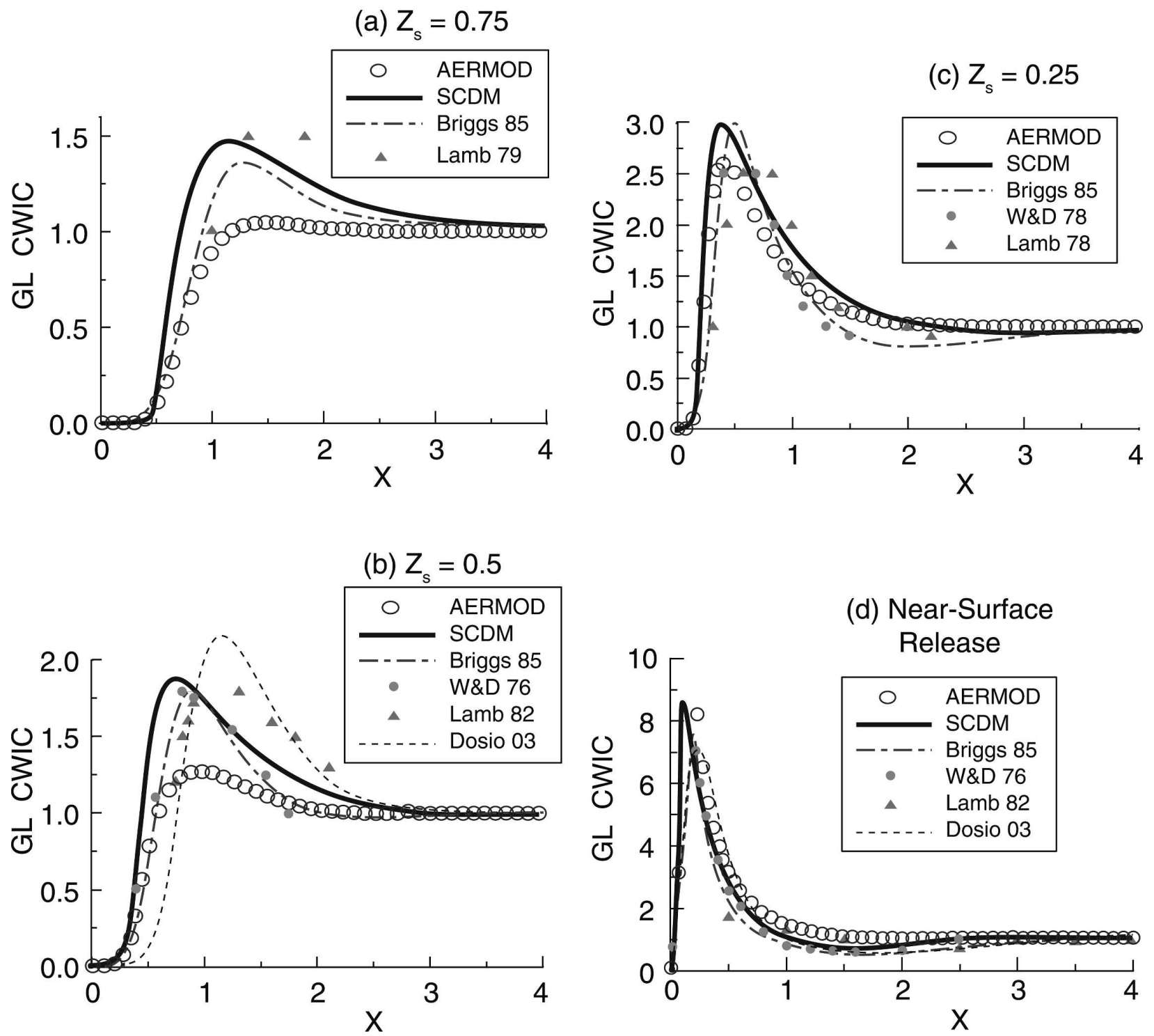

FIG. 10. Ground level (GL) crosswind-integrated concentration (CWIC) predicted by AERMOD and SCDM for different emission heights $Z_{s}$ during pure free convection. For comparison are shown the Briggs (1985) parameterization, tank simulations by WD76 and WD78, and LES by Lamb $(1978,1979,1982)$ and Dosio et al. (2003).

$$
\sigma_{z} / z_{i}=\frac{0.6 X}{\left(1+5 X^{2}\right)^{1 / 2}}
$$

for all release heights. At very large $X$, this gives $\sigma_{z} / z_{i} \approx 0.29$. For surface releases at small $X(<0.3)$, Nieuwstadt's (1980) analysis of the Prairie Grass experiments suggests that $\sigma_{z} / z_{i} \approx 0.9 X^{3 / 2}$, and for elevated releases $\sigma_{z} / z_{i} \approx 0.6 X$. These relationships are plotted in Fig. 11, along with the simulation and model data from Hibberd (2000), Luhar et al. (2000), Nieuwstadt (1992), WD76, WD78, and WD81.

Figure 11a shows vertical dispersion calculated by the SCDM agreeing with the Briggs curve and simulation data at large $X$ but underpredicting at small $X$ (i.e., at approximately $X<0.5$ ) for elevated releases and overpredicting for the surface release. On the other hand, the AERMOD (Fig. 11b) agrees fairly well with the Briggs curve.

Figure 12 shows the skewness of pollutant altitude from SCDM. Source height $Z_{s}=0.25$ was chosen to allow comparison with skewness plotted by Luhar et al. (2000), for which both approaches show similar behavior. Luhar et al. (2000) used trajectories from singleparticle Lagrangian calculations to guide parameter determination for a meandering plume model, which included relationships between skewness and spread 

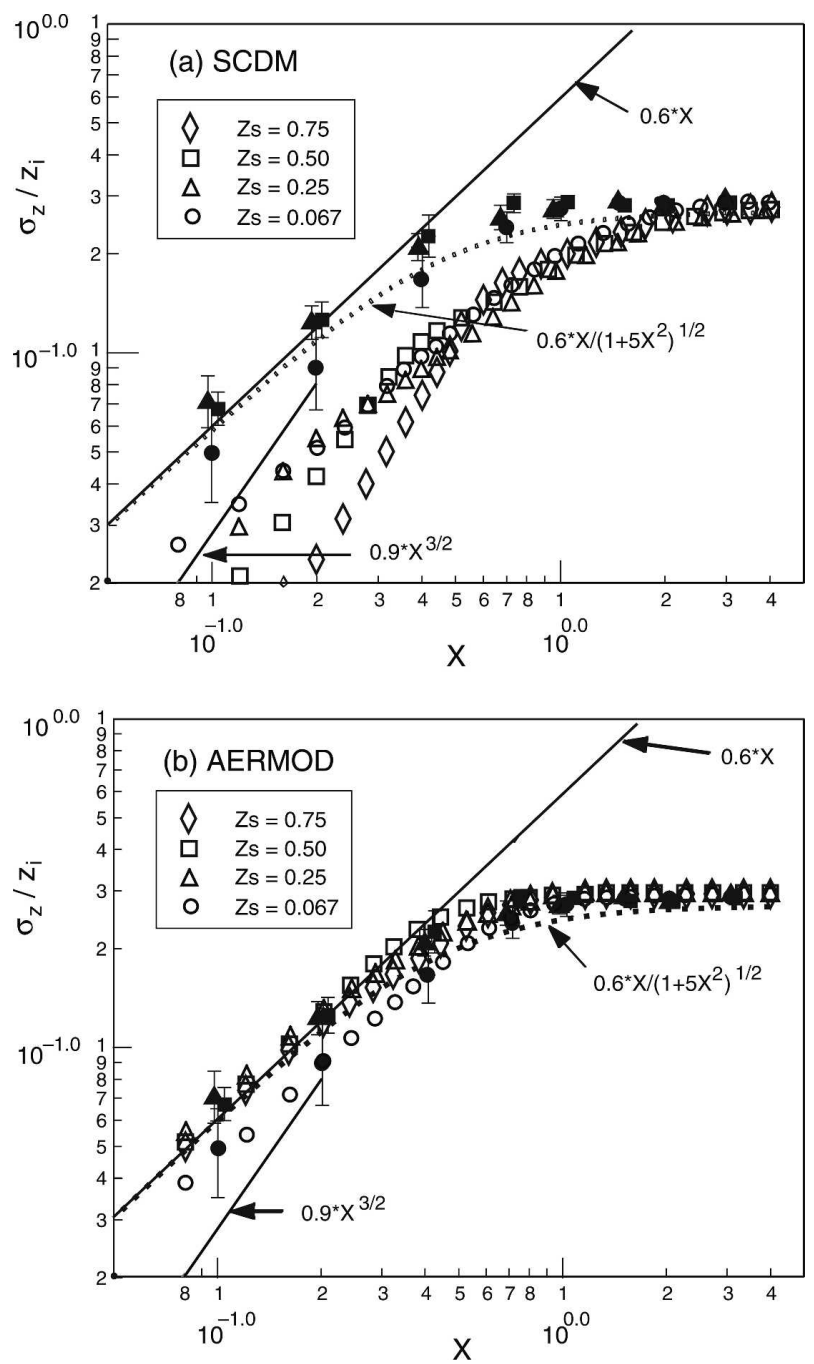

FIG. 11. Vertical dispersion parameter calculated from (a) SCDM and (b) AERMOD for pure free convection. For comparison, data from laboratory tank and LES and a Lagrangian/ meandering plume model are summarized with the whisker plots (indicating range and midpoints), each of which has at its center a solid-filled symbol of the same shape as the open symbols listed in the legend for different source heights. These include the results of Hibberd (2000), Luhar et al. (2000), Nieuwstadt (1992), WD76, WD78, and WD81. The lines with equations are from atmospheric observations, as described in the text.

caused by the transient loops (meanders) of a smoke plume in a convective ABL. Our SCDM carries no explicit information about the transient loops and has no relationship between skewness, vertical spread parameter $s$, or $\sigma_{z}$.

\section{Conclusions}

This report presents a simple model (SCDM) for dispersion of a passive, conservative tracer from a con-

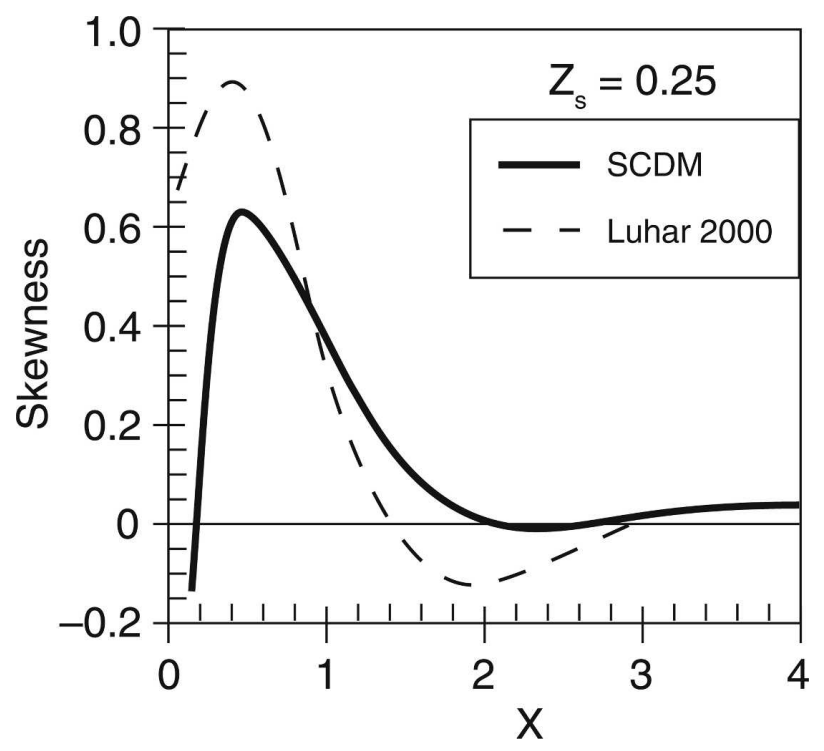

FIG. 12. Coefficient of skewness of pollutant altitude vs dimensionless downwind distance, comparing results from the SCDM with those from the Lagrangian-trajectory-informed meanderingplume model of Luhar et al. (2000).

tinuous point source in a convective ABL. A simple oscillating centerline for the time-averaged plume describes to zero order much of the complex behavior exhibited in the convective $\mathrm{ABL}$ and captures some, but not all, of the change as mechanically (shear) generated turbulence in the surface layer increasingly contributes to the predominant buoyant production. This SCDM is so simple that it is easy to solve on a computer spreadsheet, as was used to yield quickly all of the SCDM results shown in this paper. Ratio $U / w_{B}$ is also suggested as a practical alternative to $u_{*} / w_{*}$ to estimate the relative contributions of mechanical and buoyant turbulence for situations in which buoyant contributions dominate.

The vertical spread of crosswind-integrated concentration is modeled with a lognormal distribution to give better ground-level concentrations. The SCDM is calibrated using the tank studies of WD76, WD78, and WD81 and the large-eddy simulations of Lamb (1978, $1979,1982)$ and Dosio et al. (2003). This SCDM is easy to use and requires few input parameters. The $\bar{Z}$ values of Dosio et al. (2003) are bracketed by the $Z_{\mathrm{CL}}$ and $\bar{Z}$ values from the SCDM.

Dispersion characteristics of SCDM are compared with another parameterized model: AERMOD, which also has algorithms for convective dispersion. AERMOD is much more complex (requiring many user-supplied parameters) than SCDM, but both models are still much simpler than a large-eddy simulation. The SCDM produces more realistic looking CWIC isopleths and 
ground-level concentrations than AERMOD does. It also appears that AERMOD disperses pollutants too quickly in the vertical direction (other than at very small distances from the source).

To the credit of AERMOD, it is a model with much broader applicability than SCDM. AERMOD is designed as a best compromise to work in a much wider range of meteorological conditions and terrain than that for which SCDM was designed. Whereas AERMOD can be used in convective, neutral, or stable conditions, the SCDM is designed for predominantly convective conditions only. Also, SCDM does not account for shear generated aloft. AERMOD can also be used with both passive and buoyant releases whereas the SCDM is intended for passive releases only. By making use of the dividing streamline concept (Snyder et al. 1985), it could be possible to extend the SCDM to complex terrain.

Acknowledgments. This research was supported by grants from the Canadian Natural Sciences and Engineering Research Council, Environment Canada, and the British Columbia Ministry of Environment.

\section{APPENDIX}

\section{Description of AERMOD-M Runs and Variables}

For the AERMOD-M runs a general input file was used to declare the model options, provide details about the source and receptors, and direct the program to the appropriate meteorological files. The model options included flat terrain, no stack-tip downwash, a point source emitting carbon monoxide at $500 \mathrm{~g} \mathrm{~s}^{-1}$, exhaust gas exit temperature identical to the surrounding temperature (to provide a nonbuoyant release), a nominal stack velocity of $1.0 \mathrm{~m} \mathrm{~s}^{-1}$, and a stack diameter of $5.0 \mathrm{~m}$.

For the meteorological data, 19 variables describing the hourly surface meteorological conditions were passed to AERMOD-M (Table 2) for each of the three hours used in the simulation. AERMOD-M then averaged its output concentrations over this 3-h period. Meteorological data for each hour were the same, except for a change in the "observation" hour. Data describing the vertical profile of the $\mathrm{ABL}$ were also passed to AERMOD-M. The "profile" consisted of meteorological observations taken at a single mid-ABL location (Table 2). Listed below are surface and profile variables passed to AERMOD-M and the methods used to calculate them.

\section{a. Surface data}

The month, year, day, ordinal day ("Julian day" in AERMOD), and hour have been chosen to reflect con- ditions at noon on the summer solstice. The sensible heat flux $H$ is set to $300 \mathrm{~W} \mathrm{~m}^{-2}$ by adjusting the Bowen ratio $B_{o}$ and net radiation $R_{n}$ in a surface energy balance. The balance is given by

$$
H=\frac{0.9 R_{n}}{\left[1+\left(1 / B_{o}\right)\right]},
$$

with

$$
R_{n}=\frac{(1-r) R+c_{1} T_{\mathrm{ref}}^{6}-\sigma_{\mathrm{SB}} T_{\mathrm{ref}}^{4}+c_{2} n}{1+c_{3}},
$$

where $c_{1}=5.31 \times 10^{-13} \mathrm{~W} \mathrm{~m}^{-2} \mathrm{~K}^{-6}, c_{2}=60 \mathrm{~W} \mathrm{~m}^{-2}$, $c_{3}=0.12, \sigma_{\mathrm{SB}}=5.67 \times 10^{-8} \mathrm{~W} \mathrm{~m}^{-2} \mathrm{~K}^{-4}, T_{\text {ref }}$ is the temperature at reference height, and $n$ is cloud cover $[\in(0,1)]$ and is chosen to be 0.1 . Also, $r$ represents the surface albedo (chosen as 0.2 ) and $R$ is the solar radiation corrected for cloud cover:

$$
R=R_{o}\left(1-0.75 n^{3.4}\right) .
$$

Last, $R_{o}$ is the clear-sky insolation $\left(\mathrm{W} \mathrm{m}^{-2}\right)$ given by

$$
R_{o}=990 \sin \phi-30,
$$

where $\phi$ is solar elevation and is chosen to be $72^{\circ}$. The Bowen ratio was chosen to be 1.3 , typical of moderately dry conditions.

The friction velocity $u_{*}$ and Monin-Obukov length $L$ were found iteratively by using assigned values for surface roughness typical of rural locations $\left(z_{o}=0.1 \mathrm{~m}\right)$ and a reference wind speed typical of calm convective conditions $\left(U=2.75 \mathrm{~m} \mathrm{~s}^{-1}\right)$ measured at a standard reference height $\left(z_{\text {ref }}=10 \mathrm{~m}\right)$. The expression for $L$ is

$$
L=-\frac{\rho c_{P} T_{\mathrm{ref}} u_{*}^{3}}{k g H},
$$

where $g$ is accleration due to gravity $c_{P}$ is specific heat of air at constant pressure, $\rho$ is density of air, and $k$ is the von Kármán constant, equal to 0.4.

The expression for $u_{*}$ is

$$
u_{*}=\frac{k U}{\ln \left(z_{\mathrm{ref}} / z_{o}\right)-\Psi_{m}\left(z_{\mathrm{ref}} / L\right)+\Psi_{m}\left(z_{o} / L\right)},
$$

where

$$
\begin{aligned}
\Psi_{m}\left(z_{\mathrm{ref}} / L\right)= & 2 \ln \left(\frac{1+\mu}{2}\right)+\ln \left(\frac{1+\mu^{2}}{2}\right) \\
& -2 \tan ^{-1}(\mu)+\frac{\pi}{2},
\end{aligned}
$$

with

$$
\mu=\left(1-16 \frac{z_{\mathrm{ref}}}{L}\right)^{1 / 4}
$$


and

$$
\begin{aligned}
\Psi_{m}\left(z_{o} / L\right)= & 2 \ln \left(\frac{1+\mu_{o}}{2}\right)+\ln \left(\frac{1+\mu_{o}^{2}}{2}\right) \\
& -2 \tan ^{-1}\left(\mu_{o}\right)+\frac{\pi}{2},
\end{aligned}
$$

with

$$
\mu_{o}=\left(1-16 \frac{z_{o}}{L}\right)^{1 / 4}
$$

The convective mixed-layer (ABL) depth $z_{i c}$ is chosen to be $500 \mathrm{~m}$. The mechanical mixed-layer (ABL) depth $z_{\text {im }}$ was chosen to be $35 \mathrm{~m}$ to simulate almost pure free convection. In AERMOD, the mixing height $z_{i}$ is set to the maximum of the mechanical and convective depth during convective conditions. The Deardorff velocity $w_{*}$ is found from

$$
w_{*}=\left(\frac{g H z_{i}}{\rho C_{P} T_{\text {ref }}}\right)^{1 / 3} .
$$

The temperature gradient $d \theta / d z$ both in the capping interfacial layer $\left(z_{i}<z<z_{i}+500 \mathrm{~m}\right)$ and above it $\left(z>z_{i}+500 \mathrm{~m}\right)$ was set to $0.005 \mathrm{~K} \mathrm{~km}^{-1}$. The wind direction was chosen to be $270^{\circ}$ so that it blows from the west, with a reference height of $10.0 \mathrm{~m}$. The ambient temperature was taken as $300 \mathrm{~K}\left(27^{\circ} \mathrm{C}\right)$ at a reference height of $10.0 \mathrm{~m}$.

\section{b. Profile data}

The same values of year, month, day, and hour were used as were used for the surface data. A measurement height of $250 \mathrm{~m}$ above ground level was chosen for the profile data to mimic measurements taken midway in the ABL. The flag value was set to 1 so that AERMOD-M knows that this is the only set of profile data at this height. The wind direction was chosen to be the same as at the ground. The wind speed at $250 \mathrm{~m}$ above ground level was calculated using the ABL stability relationships [(A6)-(A10)] and the surface wind speed. The temperature at $500 \mathrm{~m}$ above ground was found assuming an adiabatic lapse rate $\Gamma$ of $0.0098 \mathrm{~K}$ $\mathrm{m}^{-1}$ and surface temperature of

$$
T(z)=T(0)-\Gamma z .
$$

To calculate "sigma theta," the standard deviation of horizontal wind direction $\left(\sigma_{\theta}\right)$, we first used AERMET/ AERMOD's algorithm for calculating lateral turbulence fluctuations:

$$
\sigma_{v}^{2}=3.6 u_{*}^{2}+0.35 w_{*}^{2}
$$

To convert to the horizontal wind direction fluctuations, we assumed

$$
\sigma_{\theta} \approx\left(\sigma_{v} / U\right)\left(180^{\circ} / \pi\right)
$$

which gives turbulent intensities of much less than 1 . This last step is not explicitly described in the AERMOD formulation (Cimorelli et al. 2005), and we are unsure of how it is handled in AERMOD. The vertical turbulent intensity $\sigma_{w}$ was found using

$$
\sigma_{w}^{2}=1.7 u_{*}^{2}\left(1-z / z_{i}\right)+0.35 w_{*}^{2} .
$$

\section{REFERENCES}

Arya, S. P., 1999: Air Pollution Meteorology and Dispersion. Oxford Press, $310 \mathrm{pp}$.

Briggs, G. A., 1985: Analytical parameterization of diffusion: The convective boundary layer. J. Climate Appl. Meteor., 24, 1167-1186.

- 1993: Final results of the CONDORS convective diffusion experiment. Bound.-Layer Meteor., 62, 315-328.

Cimorelli, A. J., and Coauthors, 2005: AERMOD: A dispersion model for industrial source applications. Part I: General model formulation and boundary layer characterization. $J$. Appl. Meteor., 44, 682-693.

Deardorff, J. W., 1983: A multi-limit mixed-layer entrainment formulation. J. Phys. Oceanogr., 13, 988-1002.

Dosio, A., J. V.-G. de Arellano, A. A. M. Holtslag, and P. J. H. Builtjes, 2003: Dispersion of a passive tracer in buoyancyand shear-driven boundary layers. J. Appl. Meteor., 42, 11161130.

Driedonks, A. G. M., 1982: Models and observations of the growth of the atmospheric boundary layer. Bound.-Layer Meteor., 23, 283-306.

Fedorovich, E., 2004: Dispersion of passive tracer in the atmospheric convective boundary layer with wind shears: A review of laboratory and numerical model studies. Meteor. Atmos. Phys., 87, 3-21.

_ , and J. Thäter, 2002: A wind tunnel study of gaseous tracer dispersion in the convective boundary layer capped by a temperature inversion. Atmos. Environ., 36, 2245-2255.

Hibberd, M. F., 2000: Vertical dispersion of a passive scalar in the convective boundary layer: New laboratory results. Preprints, 11th Joint Conf. on the Applications of Air Pollution Meteorology with the Air and Waste Management Association, Long Beach, CA, Amer. Meteor. Soc., 18-23.

Lamb, R. G., 1978: A numerical simulation of dispersion from an elevated point source in the convective planetary boundary layer. Atmos. Environ., 12, 1297-1304.

_ 1979: The effects of release height on material dispersion in the convective planetary boundary layer. Preprints, Fourth Symp. on Turbulence, Diffusion, and Air Pollution, Reno, NV, Amer. Meteor. Soc., 27-33.

_, 1982: Diffusion in the convective boundary layer. Atmospheric Turbulence and Air Pollution Modelling, F. T. M. Nieuwstadt and H. van Dop, Eds., D. Reidel Publishing, 159229.

Luhar, A. K., M. F. Hibberd, and M. S. Borgas, 2000: A skewed meandering plume model for concentration statistics in the convective boundary layer. Atmos. Environ., 34, 3599-3616.

Moeng, C.-H., and P. P. Sullivan, 1994: A comparison of shear- 
and buoyancy-driven planetary boundary layer flows. $J$. Atmos. Sci., 51, 999-1022.

Nieuwstadt, F. T. M., 1980: Application of mixed-layer similarity to the observed dispersion from a ground-level source. $J$. Appl. Meteor., 19, 157-162.

- 1992: A large-eddy simulation of a line source in a convective atmospheric boundary layer-I. Dispersion characteristics. Atmos. Environ., 26A, 485-495.

Perry, S. G., A. J. Cimorelli, R. F. Lee, R. J. Paine, A. Venkatram, J. C. Weil, and R. B. Wilson, 1994: AERMOD: A dispersion model for industrial source applications. Proc. of the 87th Annual Meeting of the Air and Waste Management Association, Pittsburgh, PA, Air and Waste Management Association, Paper 94-TA23.04.

— , and Coauthors, 2005: AERMOD: A dispersion model for industrial source applications. Part II: Model performance against 17 field study databases. J. Appl. Meteor., 44, 694-708.

Slade, D. H., 1968: Meteorology and Atomic Energy 1968. U.S. Atomic Energy Commission/Division of Technical Information, TID-24190, $445 \mathrm{pp}$.

Snyder, W. H., R. S. Thomson, R. E. Eskridge, R. E. Lawson, I. P. Castro, J. T. Lee, J. C. R. Hunt, and Y. Ogawa, 1985: The structure of the strongly stratified flow over hills: Dividing streamline concept. J. Fluid Mech., 152, 249-288.

Stull, R. B., 1976: The energetics of entrainment across a density interface. J. Atmos. Sci., 33, 1260-1267.
—_, 1988: An Introduction to Boundary Layer Meteorology. Kluwer/Springer, $666 \mathrm{pp}$.

- 1994: A convective transport theory for surface fluxes. $J$. Atmos. Sci., 51, 3-22.

_ 1995: Meteorology Today for Scientists and Engineers. West, $385 \mathrm{pp}$.

—- 2000: Meteorology for Scientists and Engineers. 2d ed. Brooks/Cole Thompson Learning, 502 pp.

Tennekes, H., 1973: A model for the dynamics of the inversion above a convective boundary layer. J. Atmos. Sci., 30, 558567

Wallace, J. M., and P. V. Hobbs, 2006: Atmospheric Science, An Introductory Survey. 2d ed. Springer, 483 pp.

Willis, G. E., and J. W. Deardorff, 1976: A laboratory model of diffusion into a convective boundary layer. Quart. J. Roy. Meteor. Soc., 102, 427-445.

— , and — 1978: A laboratory study of dispersion from an elevated source within a modeled convective planetary boundary layer. Atmos. Environ., 12, 1305-1311.

$\longrightarrow$, and 1981: A laboratory study of dispersion from a source in the middle of the convective mixed layer. Atmos. Environ., 15, 109-117.

Zeman, O., and H. Tennekes, 1977: Parameterization of the turbulent energy budget at the top of the daytime atmospheric boundary layer. J. Atmos. Sci., 34, 111-123. 